\title{
Do research centres herald a new era in UK academic science?
}

\section{London}

THE attention of Britain's scientific community is sharply focused on the new interdisciplinary research centres (IRCs) that will soon be sprouting up in British universities. Details of how the centres will be managed began to emerge last week. At the end of last year, the Science and Engineering Research Council (SERC) announced that the first centre, in high-temperature superconductivity, would be established at Cambridge. Earlier this month, three further centres were announced, in surface science (to be based at the University of Liverpool), molecular sciences (Oxford) and engineering design (Glasgow). A fifth centre, in synthesis and characterization of semiconductor and novel materials, will be set up at Imperial College, London, when more money is available. The Medical Research Council has expressed interest in jointly supporting the Oxford centre, as well as establishing a separate centre in toxicology. The Agricultural and Food Research Council and SERC have been discussing a joint centre in process engineering.

The importance of the IRC in shaping the future direction of academic science in Britain will depend largely on the performance of the first centres. Critics of the concept claim that directed programmes of research in large centres, often dictated by the needs of industry, will stifle initiative and are bad for science. The research councils, however, see the centres as a way of breaking down the barriers of traditional discipline-based research and encouraging vital collaboration and awareness between disciplines.

The proportion of the science budget devoted to IRC-based research is likely to increase markedly over the coming years. The Advisory Board for the Research Councils, which is largely responsible for the allocation of the science budget, said in recent advice to the government that "a large part of the councils' support for university research should eventually be channelled through these centres". The government's chief scientific adviser, $\mathrm{Mr}$ John Fairclough, has on several occasions made clear his support for IRCs.

Of the four centres announced, the surface science centre at Liverpool will receive the lion's share - $£ 10$ million over the next six years. This compares with $£ 1.3$ million that surface science at Liverpool received between 1982 and 1987. The Oxford centre expects to receive between $£ 6$ and $£ 8$ million, and the Glasgow centre around $£ 7$ million.

The centres will be managed at two levels. A local management committee will administer the daily running of the centre. Membership of the management committee will in most cases include representation from the centre, SERC and industrialists involved in any of the research programmes. Overseeing the work of the centre will be a steering group, chaired by a member of SERC and with independent industrial and overseas representation. The centres will be reviewed after two and four years. The fate of a centre will be largely determined by the steering group.

The extent of industrial involvement in the centres is likely to be considerable although SERC has suggested that in the interests of a balanced research programme, income from industrial sources should remain at around 20 per cent of the total. Supporters of the concept are convinced that IRCs will provide the route to revitalize British research, but that the success of the venture hinges on adequate financing and flexible local management to foster originality. Simon Hadlington

\section{New reform of Soviet education endorsed by Mikhail Gorbachev}

\section{London}

MAJOR changes in the pattern of Soviet education advocated by the Central Committee of the Communist Party of the Soviet Union have been endorsed by $\mathrm{Mr}$ Mikhail Gorbachev. This is the third reform of Soviet education to be offered since Gorbachev came to power exactly three years ago.

According to Gorbachev last week, the new objective is a "qualitatively new level" of education in the Soviet Union. Mr Egor Ligachev, a fellow-member of the Politburo, says that the earlier reform of vocational education, introduced in 1985 , had been prepared under the previous administration and was inadequate for the needs of perestroika.

One difficulty has apparently been that the reform had provided older secondaryschool students with "mass vocational training . . in the simplest specialities", reducing the entry of students into the last two years of secondary school and, eventually, into tertiary colleges. This, said Ligachev, runs counter to the need for ever-higher qualifications in the workforce

There is some concern at the standards attained by school-leavers. A spot-check carried out last September among 27,000 first-year students at tertiary establishments of different kinds is said to have found 25 per cent of university students, and 45 per cent of those at technical colleges, to be below minimum standards; at one engineering college, 70 per cent of students failed the mathematics test administered.

Under the proposed reform, schools and courses for talented students will be encouraged, as well as a system of specialized boarding schools attached to universities and sharing their facilities on the model of the physics and mathematics boarding schools attached to the University of Moscow. Among other elements of the proposed reform are:

- Schools will be allowed to drop the compulsory work-training previously required on the grounds that they lack the necessary time, facilities and people.

- Industry will be more closely involved in the financing of higher education and the tailoring of graduate output to job opportunities. The practice by which industrial organizations are paid 3,000 rubles for each graduate they recruit should, Ligachev noted, allow universities to collect 300 million rubles a year for the modernization of obsolete buildings and equipment.

- Universities and polytechnics will be encouraged to follow the examples of the University of Gor'kii and Tomsk Polytechnic in setting up industrial units, while the government should arrange for closer collaboration between higher education and the academies of science and the production ministries.

- Steps will be taken to free education from the "labyrinth" of rules and regulations, while institutions would be provided with better equipment and personnel.

One of the present difficulties seems to be that education rates only a low priority from the State Planning Commission, which tucks it away under "other consumers" in its budgets. Ligachev also complains about the design and condition of the buildings programme, citing the case of the Perm Polytechnic Institute, where an extension has been under construction for 20 years.

Another complaint is that too many tertiary institutions have poorly qualified staff. A particular difficulty seems to be that local authorities apply to the centre for permission to have a university in their region but then, when the institution is opened, wash their hands of it. Ligachev is for a "rigorous" survey of the Soviet Union's tertiary institutions, with a triage solution: borderline cases should be given help, but the weakest institutions should be made into local branches of stronger institutions.

Vera Rich 